\title{
High prevalence of glucokinase mutations in Italian children with MODY. Influence on glucose tolerance, first-phase insulin response, insulin sensitivity and BMI
}

\author{
O. Massa ${ }^{1}$, F.Meschi ${ }^{2}$, A. Cuesta-Munoz ${ }^{4}$, A. Caumo ${ }^{3}$, F. Cerutti ${ }^{5}$, S. Toni ${ }^{6}$, V. Cherubini ${ }^{7}$, L. Guazzarotti ${ }^{8}$, N. Sulli ${ }^{9}$, \\ F. M Matschinsky ${ }^{4}$, R. Lorini ${ }^{10}$, D. Iafusco ${ }^{11}$, F. Barbetti ${ }^{1}$ and the Diabetes Study Group of the Italian Society of \\ Paediatric Endocrinology and Diabetes (SIEDP)* \\ ${ }^{1}$ Laboratory of Molecular Pathology of Diabetes, ${ }^{2}$ Department of Paediatrics and Endocrine Unit, ${ }^{3}$ Unit of Biometrics, \\ H.S. Raffaele Scientific Institute, Milan, Italy \\ ${ }^{4}$ Department of Biochemistry and Biophysics and the Diabetes Research Center, University of Pennsylvania School of Medicine, \\ Philadelphia, USA \\ ${ }^{5}$ Department of Paediatrics, University of Turin, Turin, Italy \\ ${ }^{6}$ Regional Center for Juvenile Diabetes, Meyer Paediatric Hospital, Florence, Italy \\ ${ }^{7}$ Department of Paediatrics, University of Ancona, Ancona, Italy \\ ${ }^{8}$ Department of Paediatrics, S.Lucia Hospital, Recanati, Italy \\ 9 Department of Paediatrics, "La Sapienza" University, Rome, Italy \\ 10 Department of Paediatrics, University of Genoa, G. Gaslini Institute, Genoa, Italy \\ ${ }^{11}$ Department of Paediatrics, II University of Naples, Naples, Italy \\ * See acknowledgements
}

\section{Abstract}

Aims/hypothesis. The aim of this study was to assess the prevalence of glucokinase gene mutations in Italian children with MODY and to investigate genotype/phenotype correlations of the mutants.

Methods. Screening for sequence variants in the glucokinase gene was performed by denaturing gradient gel electrophoresis and direct sequencing in 132 children with maturity onset diabetes of the young (MODY) and in 9 children with chronic fasting hyperglycaemia but without laboratory evidence for Type I (insulin-dependent) diabetes mellitus and with normoglycaemic parents ("non-classical" MODY).

Results. Altogether 54 mutations were identified in the MODY group (54/132 or $41 \%)$ and 3 among the "non-classical" MODY individuals (3/9 or 33\%). Paternity testing indicated that the latter mutations have arisen de novo. Mean fasting plasma glucose concentrations of the children with the mutant glucokinase was in the expected impaired fasting glucose range. In contrast, results of the oral glucose tolerance test showed a wide range from normal glucose tolerance (Group 1: 2-h OGTT $=6.7 \pm 1.1 \mathrm{mmol} / \mathrm{l} ; 11$ patients) to diabetes (Group 2: 2-h OGTT $=11.5 \pm 0.5 \mathrm{~m}$ $\mathrm{mol} / \mathrm{l}$; 9 patients), with the remaining in the impaired glucose tolerance range. Disruptive mutations (i.e. nonsense, frameshifts, splice-site) were equally represented in Groups 1 and 2 and were not clearly associated with an impaired first-phase insulin response. Surprisingly, 5 out of 11 children (or $45 \%$ ) in Group 1 were found to be overweight but no children in Group 2 were overweight. Sensitivity index (SI), calculated by a recently described method, was found to be significantly lower in Group 2 than in Group 1 (SI Group $2=0.0013 \pm 0.0009 \mathrm{ml} \mathrm{Kg}{ }^{-1} \mathrm{~min}^{-1} / \mu \mathrm{U} / \mathrm{ml} ; \mathrm{SI}$ Group $1=0.0068 \pm 0.0048, p<0.0035$ ).

Conclusion/interpretation. Mutations in glucokinase are the first cause of MODY among Italian children selected through a low threshold limit of fasting plasma glucose (i.e. $>5.5 \mathrm{mmol}$ ). The lack of correlation between the molecular severity of glucokinase mutations, insulin secretion at intravenous glucose tolerance test and differences in glucose tolerance suggests that factors outside the beta cell are also involved in determining post-load glucose concentrations in these subjects. Our results seem to indicate that the differences observed in the 2-h responses at the OGTT among children with MODY 2 could be related to individual differences in insulin sensitivity. [Diabetologia (2001) 44: 898-905]

Keywords MODY 2, insulin secretion, insulin sensitivity, glucokinase, BMI, Italy.
Received: 4 December 2000 and in revised form: 05 March 2001

Corresponding author: F. Barbetti, M.D., PhD, Laboratory of Molecular Pathology of Diabetes, H.S. Raffaele Scientific Institute, Via Olgettina 60, 20132, Milan, Italy
Abbreviations: GK, glucokinase; $\mathrm{HNF} 4 \alpha, \mathrm{HNF} 1 \alpha, \mathrm{HNF} 1 \beta$; hepatocyte nuclear factor $4 \alpha, 1 \alpha, 1 \beta$; IPF-1, Insulin promoter factor 1; FPIR, first-phase insulin response; ICA, islet cell antibodies; IAA, insulin auto-antibodies; DGGE, denaturing gradient gel electrophoresis; DG-DGGE, double gradient DGGE; HOMA-IR, homeostasis model assessment index of insulin resistance. 
Maturity onset diabetes of the young (MODY) is an early-onset, autosomal dominant sub-type of Type II (non-insulin-dependent) diabetes mellitus. MODY is not uniform clinically and genetically but is caused by mutations of the enzyme glucokinase $(\mathrm{GK})$ critical to glucose homeostasis (MODY 2) [1] and by mutations of four transcription factors important in pancreatic islet cell biology (HNF $4 \alpha$, HNF $1 \alpha$, IPF-1 and HNF $1 \beta$ in MODY subtypes 1, 3, 4 and 5, respectively) [2-5]. Furthermore, a relevant subgroup of MODY cases has not been explained in molecular terms [6]. The true prevalence of MODY in European populations is not known. However, mutations in HNF $1 \alpha$ (or MODY 3) are the commonest cause of MODY in the UK, Denmark, Scandinavia, Germany, and Spain [7-10], while mutations of GK (or MODY $2)$ seem to predominate in France $[1,11]$.

Our study focuses on the role that GK mutations play a part in the pathogenesis of diabetes mellitus in Italian children. The GK (or hexokinase IV) is a biochemically unique member of the mammalian hexose phosphotransferases which is expressed in pancreatic islet cells, liver and in selected neurons and enterocytes [12-14]. The GK has been conceptualized as a glucose sensor in the pancreatic beta cell, explaining its pivotal role in glucose homeostasis [15, 16]. Individuals with GK mutations usually have a mild form of diabetes with signs of pancreatic betacell and hepatocyte dysfunction [17]. A reduction of beta-cell GK activity or amount increases the glucose threshold for insulin secretion, causing fasting hyperglycaemia which is typical of these patients [18]. Reduced hepatic GK is responsible for a decreased post-meal glycogen accumulation in the liver and increased hepatic gluconeogenesis [19] most probably contributing to the post-prandial hyperglycaemia observed in MODY 2. In general, individuals with GK mutations have normal insulin sensitivity $[17,20,21]$ but a moderate insulin resistance has been reported to develop over time [22].

The aim of our investigation was to assess the prevalence of GK mutations in MODY families who had been identified by the index case in Italian paediatric diabetes clinics. In addition, because of the reported high frequency of de novo mutations arising in the $G K$ gene $[11,23]$, we also studied subjects with chronic fasting hyperglycaemia, but lacking laboratory evidence of Type I (insulin-dependent) diabetes mellitus, and with normoglycaemic parents ("non-classical" MODY). We identified 57 mutant alleles of the glucokinase gene. The assessment of the metabolic profile of these MODY 2 patients revealed that some had unexpected discrepancies of their post-load glucose tolerance, varying from normal glucose concentrations at 120' of OGTT to diabetes. Thus, we examined whether these variations in the metabolic status might be related to differences in the molecular severity of the GK mutations, in the first-phase insulin response (FPIR), in the bodymass index (BMI) or in the insulin sensitivity.

\section{Subjects and methods}

Patients. The clinical diagnosis of MODY was made in children with diabetes or IFG using the new ADA criteria for fasting blood glucose, with a negative search for the markers of Type I diabetes (i.e. absence of ICA, IAA, ICA512 and/or anti-GAD), and with a family history of Type II diabetes or other forms of derangement of glucose metabolism often found in families with GK mutations, such as gestational diabetes (GD) or IGT for at least two consecutive generations $[17,20,21]$. A family tree showing bi-lineal inheritance for Type II diabetes was not considered a criterion of exclusion. Probands were also detected through a study identifying subjects in early stages of altered glucose homeostasis of Type I diabetes, enrolling all children with an "incidental" fasting hyperglycaemia equal to or above the threshold of $5.5 \mathrm{mmol} / \mathrm{l}$, confirmed by a second fasting plasma glucose determination. The threshold was chosen as the value exceeding by two SD the mean of fasting plasma glucose of normal Italian children. Using these criteria, we collected slightly more than 300 families throughout Italy. The entire glucokinase gene has been scanned in 132 families by denaturing gradient gel electrophoresis (DGGE) and has been partially scanned in 60 other families. Because mutations in the $G K$ gene could arise de novo [11, 23, and D. Iafusco, personal communication] the screening was also extended to 9 children with diabetes (or IFG) and no humoral sign of autoimmunity whose parents have normal glucose tolerance ("non-classical MODY"). A total of 60 parents with normal fasting glucose (i.e. $<6.1 \mathrm{mmol}$ ) and no family history of diabetes served as control subjects.

Clinical studies. The probands underwent a standard IVGTT ( $0.5 \mathrm{~g} / \mathrm{kg}$ body weight), right after confirmation of hyperglycaemia and before any form of therapy was initiated. The sum of insulin values at min 1 and 3 of IVGTT was considered as a measure of the FPIR and compared to the FPIR of 136 Italian children who acted as the control group divided according to the pubertal stage [24].

About $80 \%$ of these patients also underwent an OGTT for diagnostic purposes (with insulin assay) and the glucose concentration measured at $120 \mathrm{~min}$ of the OGTT, denoted as $\mathrm{G}_{120}$, was used to classify the subjects.

Assessment of insulin sensitivity. We used two different methods to measure insulin sensitivity in the subjects with $G K \mathrm{mu}-$ tations and normal OGTT (Group 1) and in those with the 2$\mathrm{h}$ glucose value in the diabetic range (Group 2). We used the fasting glucose and insulin values measured immediately before the OGTT (time 0) to calculate the homeostasis model assessment index of insulin resistance (HOMA-IR) according to the formula HOMA-IR = [baseline insulin concentration $(\mu \mathrm{U} /$ $\mathrm{ml}) \cdot$ baseline glucose concentration $(\mathrm{mmol} / \mathrm{l})] / 22.5$. In addition, we used the glucose and insulin determinations during the OGTT at $0,30,60,90,120$, and $180 \mathrm{~min}$ (the 180 -min sample was available in 3 of the 10 subjects belonging to Group 1 and in 7 of the 8 subjects belonging to Group 2) to calculate a recently proposed minimal-model-based index of insulin sensitivity, $\mathrm{S}_{\mathrm{I}(\text { oral })}$ [25]. Briefly, calculation of $\mathrm{S}_{\mathrm{I}}$ (oral) requires the investigator to insert values for glucose effectiveness $(\mathrm{GE})$ and for the fraction of ingested glucose that actually appears in the systemic circulation denoted f (i.e., survives gastrointestinal absorption and one-pass hepatic uptake). Generally, indi- 


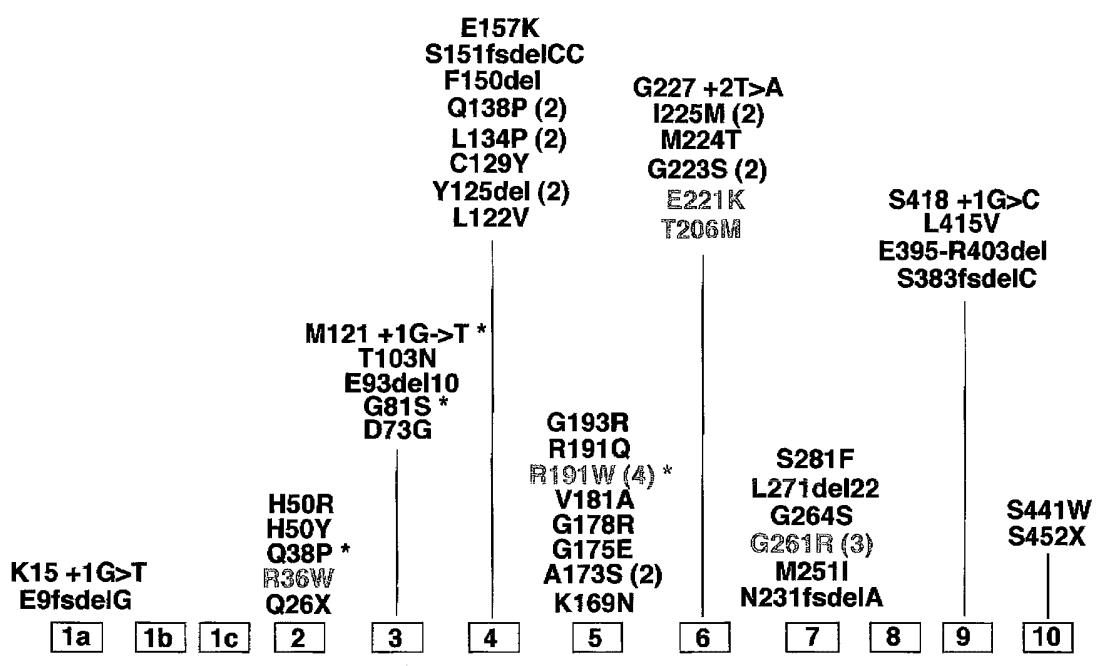

Fig. 1. Glucokinase mutations found in Italian children with the clinical features of MODY. Mutations found in two different populations and located in the same residues/nucleotides are in light blue font. An asterisk (*) denotes de novo mutations

vidual estimates of GE and $\mathrm{f}$ are not available, and thus mean values derived from the literature must be used. In the present study GE was fixed at $0.024 \mathrm{dl} / \mathrm{kg}$ min and $\mathrm{f}$ at 0.8 [25].

Amplification of the GK gene, DGGE, DNA sequencing. The polymerase reaction (PCR) of the 10 exons of the $G K$ gene was done using primer sequences previously described [26, 27]. New primers set by analysing the melting behaviour of each individual exon were also designed to obtain the most favourable DGGE experimental conditions [28] (primer sequences upon request). The DGGE, and in the case of two exons, double-gradient DGGE (DG-DGGE) experiments were conducted as described previously $[29,30]$. The DNA sequencing of PCR samples migrating abnormally in DGGE were performed using the BigDye terminator sequencing kit (Perkin Elmer Applied Bio Systems, Foster City, Calif., USA) on a ABI DNA sequencing apparatus 373A (Perkin Elmer).

Paternity test. The DNA profiling of 15 independent polymorphic loci was done using the AMPFISTR Profiler and AMPFISTR SGM plus kits (PE Biosystems) following the manufacturer's instructions. Amplicons were run on an ABI 373A sequencer (Perkin Elmer) and automatically read by the Local Southern method, Genescan 3.1 software, Genotyper 2.0. Statistical calculations were carried out with the Essen Moller's formula and available Italian frequency data of alleles. The probability of paternity (W) has been computed by a compound calculation assuming independent segregation of the polymorphic loci located on unlinked chromosomal regions.

Assessment of molecular severity of $G K$ mutations. The new structural model of $G K$ with its binding sites for glucose and $\mathrm{MgATP}^{2-}$ was used to predict the molecular severity of missense mutations [31]. Nonsense mutations, deletions, frameshifts and splice-site mutations were considered as "severe", i. e. equivalent to nonsense mutations.

Statistical analysis. Data are expressed as means \pm SEM, unless stated otherwise. To evaluate differences in $\mathrm{G}_{120}$, HOMA-IR, and $\mathrm{S}_{\mathrm{I}(\text { oral })}$, in the subjects with normal or diabetic OGTT, we used the nonparametric Mann-Whitney test. Linear regression analysis was used to study the relation between FPIR values calculated from the IVGTT and the insulin concentrations measured at $30 \mathrm{~min}$ of the OGTT. Statistical calculations were made using the Statview package for Macintosh. A $p$ value of less than 0.05 was considered statistically significant.

\section{Results}

Prevalence of glucokinase gene mutations. A total of 54 mutations were detected in the index case of the 132 MODY pedigrees in which the molecular scanning of the gene has been performed $(41 \%)$. In all families the mutation was present in every subject with hyperglycaemia and in none of the normoglycaemic relatives. In one case only (designated TO$12 / \mathrm{Q} 38 \mathrm{P}$ ) was the mutation not found in the diabetic mother or in the euglycaemic father.

Evidence of de novo mutations in glucokinase. Three of the nine children with chronic fasting hyperglycaemia, negative for serological markers of Type I (insulin-dependent) diabetes mellitus and glucose-tolerant parents ("non-classical MODY"), carried a GK mutation $(33 \%)$. As expected, DNA sequencing of the parents of the "non-classical" MODY 2 (designated TN-1/G81S, TO-17/M121 $\pm 1 \mathrm{G}->\mathrm{T}$, NA-34/ R191W) disclosed two wild-type alleles. Paternity was established with high probability $(\mathrm{W}>99.99 \%)$ in the three nuclear families (TN-1, TO-17, NA-34) and in family TO12/Q138P, strongly suggesting that all these mutations arose de novo.

A total of 47 of the 57 mutations detected are novel mutations. We found 31 missense mutations (Fig. 1: R36W, Q38P, H50Y, H50R, D73G, G81S, T103N, L122V, C129Y, L134P, Q138P, E157K, K169N, A173S，G175E，G178R，V181A，R191W，R191Q, G193R，T206M，E221K，G223S，M224T，I225M, M251I, G261R, G264S, S281F, L415V, S441W). Some of those were detected in two or more appar- 
Table 1. Clinical features of GK mutants differing for $\mathrm{G}_{120}$ of OGTT ${ }^{\mathrm{a}}$

\begin{tabular}{|c|c|c|c|c|c|c|}
\hline Patient/mutation/sex & $\begin{array}{l}\text { Fasting plasma } \\
\text { glucose } \mathrm{mmol} / \mathrm{l}\end{array}$ & $\begin{array}{l}\text { Fasting insulin } \\
\mu \mathrm{U} / \mathrm{ml}\end{array}$ & $\mathrm{G}_{120}$ & Relative BMI & FPIR & Bi-lineage \\
\hline \multicolumn{7}{|l|}{ Group 1} \\
\hline 1) $\mathrm{MI}-36 / \mathrm{Q} 26 \mathrm{X} / \mathrm{F}$ & 6 & 6.3 & 4.4 & $\geq>97^{\circ}$ & 43 & No \\
\hline 3) $\mathrm{TV}-2 / \mathrm{T} 103 \mathrm{~N} / \mathrm{M}$ & 5.5 & 7 & 7 & $\overline{75^{\circ}-90^{\circ}}$ & 46 & No \\
\hline 4) $\mathrm{TV}-1 / \mathrm{Q} 138 \mathrm{P} / \mathrm{M}$ & 6.5 & 6.6 & 5.7 & $50^{\circ}$ & 36 & Yes \\
\hline 5) $\mathrm{AN}-20-\mathrm{a} / \mathrm{A} 173 \mathrm{~S} / \mathrm{F}$ & 6.3 & 4.2 & 7.3 & $>90^{\circ}$ & & Yes \\
\hline 8) $\mathrm{MI}-28 / \mathrm{G} 175 \mathrm{E} / \mathrm{F}$ & 6.2 & 1 & 7.8 & $25^{\circ}$ & & No \\
\hline 9) $\mathrm{AN}-6 / \mathrm{G} 193 \mathrm{R} / \mathrm{M}$ & 6.4 & 2.3 & 8 & $10^{\circ}$ & 52 & No \\
\hline 10) $\mathrm{MI}-4 / \mathrm{G} 261 \mathrm{R} / \mathrm{F}$ & 6.7 & 8 & 6 & $3^{\circ}$ & 42 & No \\
\hline 11) $\mathrm{CO}-1 / \mathrm{S} 418+1 \mathrm{G}->\mathrm{C} / \mathrm{F}$ & 6.7 & 8 & 5.8 & $\geq>97^{\circ}$ & 41 & No \\
\hline Mean & 6.3 & & 6.7 & $\overline{\mathrm{OW}}=45 \%$ & 53.6 & \\
\hline SD & 0.32 & & 1.1 & & 20.5 & \\
\hline 4) $\mathrm{RM}-\mathrm{C}-2 / \mathrm{F} 150 \mathrm{del} / \mathrm{M}$ & 5.7 & 11 & 11.2 & $75^{\circ}$ & 135 & No \\
\hline 5) $\mathrm{AN}-10-\mathrm{b} / \mathrm{A} 173 \mathrm{~S} / \mathrm{M}$ & 6.1 & 6.9 & 11.2 & $50^{\circ}$ & 145 & No \\
\hline 6) $\mathrm{MO}-4 / \mathrm{V} 181 \mathrm{M} / \mathrm{M}$ & 6.7 & 6.9 & 11.2 & $3^{\circ}-10^{\circ}$ & 94 & No \\
\hline 7) $\mathrm{RN}-1 / \mathrm{R} 191 \mathrm{Q} / \mathrm{F}$ & 6.7 & & 11.5 & $25^{\circ}$ & 64 & No \\
\hline 8) $\mathrm{AN}-13 / \mathrm{T} 206 \mathrm{M} / \mathrm{M}$ & 6.4 & 9.1 & 11.1 & $25^{\circ}-50^{\circ}$ & 62 & No \\
\hline 9) $\mathrm{MI}-8 / \mathrm{G} 227+2 \mathrm{~T}->\mathrm{A} / \mathrm{M}$ & 6.2 & 9 & 12.1 & $50^{\circ}$ & & No \\
\hline Mean & 6.3 & & $11.5 \mathrm{a}$ & $\mathrm{OW}=0$ & 88.6 & \\
\hline SD & 0.32 & & 0.5 & & 47.4 & \\
\hline
\end{tabular}

${ }^{\mathrm{a}} \mathrm{G}_{120}=$ plasma glucose at 120' of OGTT. OW, overweight; individuals with a relative BMI > 90 centile of corresponding age are underlined. ${ }^{a}=p<0.001$ Group 2 vs Group 1

ently unrelated families, residing in different parts of Italy: L134P (twice), Q138P (twice), R191W (four times), G223S (twice), I225M (twice), G261R (three times) (Fig. 1). All but seven of these mutations were novel, i.e. R36W (24), R191W (35), G261R (1) and Q38P, A173S, T206M and E221K which had been previously found in other Italian families screened abroad [34 and D. Iafusco, personal communication], or in Sardinia [35] or in our laboratory [36]. In particular, the family with the A173S mutation referred to us was clearly related (identical last name) to another family living in the same area [34]. Among the other mutations, two were nonsense mutations (Q26X, $\mathrm{S} 452 \mathrm{X}$ ) and four were substitutions of a conserved nucleotide at a splice donor site $(\mathrm{K} 15+1 \mathrm{G}>\mathrm{T}$, $\mathrm{M} 121+1 \mathrm{G}->\mathrm{T}, \mathrm{G} 227+2 \mathrm{~T}->\mathrm{A}, \mathrm{S} 418+1 \mathrm{G}->\mathrm{C})$. The $\mathrm{K} 15+1 \mathrm{G}>\mathrm{T}$ mutation has been found in another Italian family [D. Iafusco, personal communication]. The remaining mutations were single or multiple nucleotide deletions resulting in frameshifts (E9fsdelG, S151fsdelCC, N231fsdelA, S383fsdelC, E93del10, L271del22) and intra-exonic multiple nucleotides in-frame deletions (Y125del, F150del, E395-R403del). The Y125del mutation has been detected in two unrelated families.

We found mutations scattered throughout the coding sequence of the $G K$ gene but, in distinction from other groups, we did not identify any mutation in exon 8 (Fig.1). This result prompted us to sequence exon 8 directly in order to exclude DGGE failure in correctly detecting nucleotide changes in this fragment of DNA. Sequence analysis of exon 8 of 54 probands randomly chosen out of the 81 MODY subjects with no evidence of GK mutation after DGGE screening disclosed 108 wild-type alleles.

The DGGE experiments in normal control subjects showed either normal electrophoretic migration or abnormally migrating patterns which corresponded, at sequencing, to previously described polymorphisms. In two families a new polymorphism was detected in intron $2(-8 \mathrm{G}->\mathrm{A})$.

Characterisation of patients with normal and diabetic glucose tolerance based on $2 h$ values. The mean age at the first observation of hyperglycaemia (mean fasting plasma glucose: $6.8 \pm 0.6 \mathrm{mmol} / \mathrm{l}$ in two separate occasions) of children with a GK mutant allele was $7.3 \pm 3.3$ years. Most of the patients who underwent an OGTT were classified as belonging to the IGT category. However, two groups with an identical mean fasting plasma glucose (Group $1=6.3 \pm 0.32$ vs Group $2=6.3 \pm 0.32 \mathrm{mmol} / \mathrm{l}$ ), but differing for $\mathrm{G}_{120}$ $(6.7 \pm 1.1$ vs $11.5 \pm 0.5 \mathrm{mmol} / 1, p<0.001$, Table 1$)$, were also identified. In this evaluation the metabolic data of two previously identified GK mutants [36, 37] were also included. 
In terms of molecular severity of the mutations found, disruptive mutations were equally represented in the two groups (Group 1: MI-36/Q26X, PV-6/ E93del10, CO-1/S418 + 1G-> C; Group 2: MI-6/ E9fsdelG, RM-C-2/F150del, MI-8/G227 + 2T-> A) and a single missense mutation with predicted strong effect on kinetic properties of the enzyme was present in Group 1 (MI-4/G261R) and in Group 2 (G80S). Of note, the same missense mutation to have only a minor predicted kinetic effect (A173S) was carried by individuals (belonging to different families) in both groups.

In general, the analysis of IVGTT tests (from 49 subjects, including four pairs of siblings; 39 different mutations) showed that FPIR was impaired (i.e. below the 1st centile of Italian children who acted as control subjects) [24] in about half the cases (23 subjects, or $47 \%)(38.6 \pm 12.6 \mu \mathrm{U} / \mathrm{ml} ; 50$ th centile $=$ $145 \mu \mathrm{U} / \mathrm{ml}$ ). Furthermore, FPIR values showed a correlation with the insulin levels at 30' of the OGTT $(p<0.0001$ by linear regression analysis: $r=0.71$, not shown). In the two groups under investigation however (Table 1), no correlation was observed between the FPIR values and the metabolic status of the patients.

Fasting serum insulin concentrations before the OGTT were very similar in both groups (Group $1=5.4 \pm 1.1$ vs Group $2=8.1 \pm 1.1 \mu \mathrm{U} / \mathrm{ml}$; NS), but the HOMA-IR index was $1.51 \pm 0.32$ vs $2.22 \pm 0.29 \mathrm{mmol} / 1 \mu \mathrm{U} / \mathrm{ml}(p=0.06)$ in Group 1 and Group 2, respectively. Furthermore, the $\mathrm{S}_{\mathrm{I} \text { (oral) }}$ index was $60.6 \pm 12.810^{-4} \mathrm{dl} / \mathrm{kg}$ min per $\mu \mathrm{U} / \mathrm{ml}$ in subjects with normal glucose tolerance (Group 1) and $12.5 \pm 3.3(p<0.01)$ in those with $\mathrm{G}_{120}$ in the diabetic range (Group 2).

We then evaluated the effect of body composition on glucose tolerance, using the body mass index (BMI, $\mathrm{kg} / \mathrm{m}^{2}$ ) of these subjects by plotting the result against the BMI charts for French children produced by Rolland-Cachera (relative BMI) [38]. Subjects with a BMI equal to or exceeding the 90th centile of normal subjects were considered overweight/obese [39]. Surprisingly, 5 of the 11 subjects belonging to Group 1 were found to be overweight/obese. The high BMI of these individuals did not apparently influence the FPIR values [40]. In contrast, all individuals classified as diabetic by the OGTT (Group 2) were lean (Table 1).

\section{Discussion}

In a nationwide effort aimed at identifying families with the clinical definition of MODY, we recruited more than 300 children with diabetes, IFG and/or IGT and a positive family history for glucose metabolism disturbances for at least two consecutive generations. After complete screening of the $G K$ gene in
132 MODY families, we identified 54 different mutations $(41 \%)$. A similar incidence has been obtained in another group of 46 Italian MODY families recruited in three paediatric centres (19 mutations or $41.3 \%$; reference 34 and D. Iafusco, R. Lorini, personal communications) and studied abroad (J. Dausset Foundation). The screening of the MODY 3 gene on the same 46 families led to the identification of six HNF $1 \alpha$ mutations (13\%), a result that is confirmed in our MODY 2-negative individuals (O. Massa, F. Barbetti, unpublished observations). The fact that higher prevalence of GK than HNF $1 \alpha$ mutations in Italian families is in contrast with the data from the UK, Denmark and Scandinavia where $58-65 \%$ of all MODY cases have the MODY 3 gene [7-9], but it is in agreement with the higher percentage of GK mutations found in French families [1, 6, 11]. The recruitment source of subjects/families used in Italy (paediatric setting) was different from the one used in the UK, Denmark and Scandinavia (adult setting) and could account for some of this discrepancy. It is probable that adults with GK mutations (i.e. mild hyperglycaemia and no other metabolic symptoms) go to a general pratictioner and not a diabetes clinic. However, ethnic differences could play a part. An investigation into mutations in the $G K$ gene in nine MODY families from Sardinia [35], a region whose population is known to have genetic differences from the rest of the Italian population, and not included in our study, has identified only two mutations $(22 \%)$. It is not clear whether the difference in results from our data is due to the relatively low number of patients or to difficulties in identifying individuals with MODY peculiar to this region, which incidentally has an unusually high prevalence of Type I diabetes.

Of note, our observations of "non-classical MODY" showed that several GK mutations associated with hyperglycaemia were found in patients with no evidence of autoimmune diabetes and with normoglycaemic parents (3/9 subjects screened here). These mutations could indeed be the cause of hyperglycaemia, even though there is no association with diabetes in the extended family in these three cases. This conclusion is supported by the fact that one mutation $(\mathrm{M} 121 \pm 1 \mathrm{G}->\mathrm{T})$ is a splice-site mutation, which probably results in an inactive protein. Furthermore, the G81S mutation is predicted to have a major impact on GK function by structural analysis and analogy with known contiguous mutations G80S, G80A [11, 32, 36]. The R191W mutation has also been detected in two other Italian families and in a British case [33] associated with hyperglycaemia in affected kin. Finally, mutations apparently arising de novo in the $G K$ gene have been described previously $[11,23]$, although paternity testing was performed in one case only [11]. Otherwise, we were able to establish paternity by DNA profiling in all 
three cases (TN-1, TO-17, NA-34) and in another family (TO-12) in which the diabetic mother did not carry the GK mutation. From the clinical point of view our data indicate that, even in the absence of a family history of diabetes, a search for GK mutations in children with mild fasting hyperglycaemia is a worthwhile strategy and could be useful for subsequent genetic counselling. Furthermore the $G K$ gene seems to be particularly prone to develop de novo mutations compared to HNF-1 $\alpha$ /MODY 3 (one de novo mutation reported in the literature [41] and A. T. Hattersley, personal communication).

The identification of 57 GK mutations in young Italian children with the MODY syndrome expands the number of currently known, naturally occurring mutations of this enzyme to just over 130 [42]. As in previous studies, this included missense and nonsense mutations, splice variants (donor and acceptor site mutations), frame-shifts and deletions. A glance at Figure 1 shows that the mutations are distributed nearly uniformly over the entire enzyme. It is likely that the majority of these molecular lesions result in proteins that are inactive or have reduced catalytic function. This is certainly the case for nonsense mutations, splice variants, frame-shifts and deletions. The variable functional consequences of missense mutations are predictable (in part at least) from the recent structural model of human beta-cell GK and from the results of previous kinetic studies of recombinant mutant GK studies in MODY-2 [32]. This analysis could then be used to classify missense mutations into two broad groups with moderate and severe catalytic impairment. However, reliable knowledge on the functional consequences of the missense mutations can only be obtained by more careful kinetic studies of recombinant enzymes of the kind already performed $[31,32,43]$. The collection of this large number of GK mutations represents a unique resource for functional and structural exploration of the GK molecule. Furthermore, a recent patent release describes the discovery of a potent new drug that activates GK allosterically (pn WO200058293-A2). It therefore might be possible in the near future to use specific GK activators in the therapy of selected cases of MODY-2.

The cohort of Italian children with the MODY 2 syndrome presents a clinical group picture very similar to that described previously for groups recruited from older populations. The fasting blood sugar is about $7.0 \mathrm{mmol} / \mathrm{l}$, the $\mathrm{HbA}_{1 \mathrm{c}}$ values are only moderately higher, ketosis is absent and in most case the outcome of OGTT is commensurate with a diagnosis of impaired glucose tolerance. However, we also observed two groups of subjects (about $20 \%$ of our data set) with relatively broad differences in glucose tolerance. We therefore wondered whether firstphase/early-phase insulin secretion values, which are considered important for efficient suppression of the hepatic glucose production [44] and ultimately for optimal glycaemic control [45-47] could correlate with glucose values at 120' of OGTT and possibly account for the discrepancy. We found that first-phase insulin response was impaired in almost $50 \%$ of the children with a $G K$ mutation, and that FPIR correlated with early-phase (30') insulin secretion at OGTT ( $p<0.0001$ by regression analysis), but neither of these two parameters correlated with glucose tolerance and/or molecular severity of the $G K$ mutation. In contrast, applying a recently described method for the evaluation of insulin sensitivity [25], we found that subjects with an OGTT glucose profile in the diabetes range are less insulin sensitive $(p<0.01)$ than subjects with normal glucose tolerance. We speculate that the individual differences in insulin sensitivity between children with $G K$ mutations might be linked to common diabetogenes of weak effect and/or other modifier genes. Although we have usually found consistently similar FPIR values from different IVGTT tests obtained in the same MODY 2 patient over time, we are aware that both IVGTT and OGTT cannot be considered the gold standard for evaluating insulin secretion and sensitivity and that our data are to be interpreted cautiously. In this context it is remarkable - and not easily explained that an increased BMI does not lead to a deterioration of glucose tolerance. In fact, there is a trend towards amelioration of the MODY 2 syndrome, which is in striking contrast to the negative impact of obesity in typical Type II diabetic adults.

Our clinical and molecular genetic results have highly practical implications for the diagnosis and the genetic counselling of children with MODY 2 and their families. The objective of molecular medicine is to arrive at a precise molecular diagnosis of diseases to develop a rational treatment plan. Modelling data obtained by methods described previously [32] clearly show that a moderately inactivating $G K$ mutation characterized by low activity index of GK [32] should pose much less of a problem for individuals and their offspring than a severely inactivating mutation, which could be lethal if in both alleles. The implications for genetic counselling are obvious, as is the need of obtaining a comprehensive biochemical characterization of each $G K$ mutant. The molecular diagnosis of $G K$ disease should include detailed information on the functional significance of the particular lesion. It should state whether one or both alleles are affected (i.e. GK $+/-$ or GK-l-), what the genetic defect is (e.g. E70K or E70X, etc.) and what the GK activity index is (e.g. 0.3 for a moderately severe inactivating mutant, 2.0 for an activating mutant, etc.) $[32,48]$.

Acknowledgements. This work has been supported by a grant (no. RF97.19) from the Italian Ministry of Health to F. Barbetti and by Telethon grant (E.098 and E.0946) to F. Barbetti. We would like to thank the following people for their help: 
A. Alibrandi, E. Angius, R. Bonfanti, P. Borboni, S. Bernasconi, F. Cadario, L. Calisti, M. Cappa, V. Cauvin, G Chiumello, M. Cicchetti, G. Contreas, A. Crinò, G. D' Annunzio, A. Franzese, P. Frongia, D. Iafusco, L. Iughetti, G. Magro, G. Marietti, M. Martinucci, C. Meossi, G. Multari, I. Rabbone, A. Scaramuzza, M. Vanelli, R. Vanini, A. Visentin, P. Vitullo for referring MODY families. We are indebted to I.T. Weber of the Department of Microbiology and Immunology, Thomas Jefferson University, Philadelphia; to S. E. Stayrook of the Department of Biochemistry and Biophysics, University of Pennsylvania School of Medicine Philadelphia and to P. D' Ursi of Mario Negri Institute, Milan for the structural analysis of GK missense mutations. The contribution of Dr. A. Piccinini, Institute of Legal Medicine, University of Milan, is also acknowledged.

\section{References}

1. Froguel P, Zouali H, Vionnet $\mathrm{N}$ et al. (1993) Familial hyperglycemia due to mutations in glucokinase. $\mathrm{N}$ Engl $\mathrm{J}$ Med 328: 687-702

2. Yamagata K, Furuta H, Oda N et al. (1996) Mutations in the hepatocyte nuclear factor-4-alpha gene in maturity-onset diabetes of the young (MODY 1). Nature 384: 458-460

3. Yamagata K, Oda N, Kaisaki PJ et al. (1996) Mutations in the hepatocyte nuclear factor-1-alpha gene in maturity-onset diabetes of the young (MODY 3 ) Nature 384: 455-458

4. Stoffers DA, Ferrer J, Clarke WL, Habener JF (1997) Early-onset type II diabetes mellitus (MODY 4) linked to IPF 1. Nat Genet 17: 138-139

5. Horikawa Y, Iwasaki N, Hara M et al. (1997) Mutation in hepatocyte nuclear factor $1 \beta$ gene (TCF2) associated with MODY. Nat Genet 17: 384-385

6. Chèvre J-C, Hani EH, Boutin P et al. (1998) Mutation screening in 18 Caucasian families suggest the existance of other MODY genes. Diabetologia 41: 1017-1023

7. Beards F, Frayling T, Bulman M et al. (1998) Mutations in the hepatocyte nuclear factor $1 \beta$ are not a common cause of maturity-onset diabetes of the young in the UK. Diabetes 47: 1152-1154

8. Letho M, Wipemo C, Ivarsson S-A et al. (1999) High frequency of mutations in MODY and mitochondrial genes in Scandinavian patients with familial early-onset diabetes. Diabetologia 42: 1131-1137

9. Lindner TH, Cockburn BN, Bell GI (1999) Molecular genetics of MODY in Germany. Diabetologia 42: 121-123

10. Costa A, Bescos M, Velho G et al. (2000) Genetic and clinical characterisation of maturity-onset diabetes of the young in Spanish families. Eur J Endocrinol 142: 380-386

11. Velho G, Blanché H, Vaxillaire M et al. (1997) Identification of 14 new glucokinase mutations and description of the clinical profile of 42 MODY-2 families. Diabetologia 40: 217-224

12. Inedjian PB (1993) Mammalian glucokinase and its gene. Biochem J 293: 1-13

13. Silver IA, Erecinska M (1998) Glucose-induced intracellular ion changes in sugar-sensitivity hypotalamic neurons. J Neuorphysiol 79: 1733-1745

14. Jetton TL, Liang Y, Pettepher CC et al. (1994) Analysis of upstream glucokinase promoter activity in transgenic mice and identification of glucokinase in rare neuroendocrine cells in the brain and gut. J Biol Chem 269: 3641-3654

15. Matschinsky FM (1990) Glucokinase as glucose sensor and metabolic signal generator in pancreatic beta-cells and hepatocytes. Diabetes 39: 647-652
16. Matschinsky FM (1996) Banting Lecture 1995. A lesson in metabolic regulation inspired by the glucokinase glucose sensor paradigm. Diabetes 45: 223-241

17. Velho G, Froguel P (1998) Genetic, metabolic and clinical characteristics of maturity onset diabetes of the young. Eur J Endocrinol 138: 233-239

18. Byrne MM, Sturis J, Clement K et al. (1994) Insulin secretory abnormalities in subjects with hyperglycemia due to glucokinase mutations. J Clin Invest 93: 1120-1130

19. Velho G, Petersen KF, Perseghin G et al. (1996) Impaired hepatic glycogen synthesis in glucokinase-deficient (MODY 2) subjects. J Clin Invest 98: 1755-1761

20. Bell GI, Pilkis SJ, Weber IT, Polonski KS (1996) Glucokinase mutations, insulin secretion, and diabetes mellitus. Annu Rev Physiol 58: 171-186

21. Hattersley AT (1998) Maturity-onset diabetes of the young: clinical heterogeneity explained by genetic heterogeneity. Diabet Med 15: 15-24

22. Clément K, Pueyo ME, Vaxillaire M et al. (1996) Assessment of insulin sensitivity in glucokinase-deficient subjects. Diabetologia 39: 82-90

23. Hager J, Blanché H, Sun F et al. (1994) Six mutations in the glucokinase gene identified in MODY by using a nonradioactive sensitive screening technique. Diabetes 43: 730-733

24. Lorini R, Vanelli M (1996) Normal values of first-phase insulin response to intravenous glucose in healthy Italian children and adolescents. Diabetologia 39: 370-371

25. Caumo A, Bergman RN, Cobelli C (2000) Insulin sensitivity from meal tolerance tests in normal subjcets: a minimal model index. J Clin Endocrinol Metab 85: 4396-4402

26. Stoffel M, Froguel P, Takeda J et al. (1992) Human glucokinase gene: isolation, characterization, and identification of two missense mutations linked to early-onset non-insulindependent (type 2) diabetes mellitus. Proc Natl Acad Sci USA 89: 7698-7702

27. Eto K, Sakura H, Shimokawa K et al. (1993) Sequence variations of the glucokinase gene in Japanese subjects with NIDDM. Diabetes 42: 1133-1137

28. Lerman LS, Silverstein K (1987) Computational simulation of DNA melting and its application to denaturing gradient gel electrophoresis. Methods Enzymol 155: 482-501

29. Barbetti F, Gejman PV, Taylor SI et al. (1992) Detection of mutations in the insulin receptor gene by denaturing gradient gel electrophoresis. Diabetes 41: 408-415

30. Cremonesi L, Carrera P, Cardillo E et al. (1998) Optimized detection of DNA point mutations by double gradient DGGE. Clin Chem Lab Med 36: 959-961

31. Mahalingam B, Cuesta-Munoz A, Davis EA, Matschinsky FM, Harrison RW, Weber IT (1999) Structural model of human glucokinase in complex with glucose and ATP: implications for the mutants that cause hypo- and hyperglycemia. Diabetes 48: 1698-1705

32. Davis EA, Cuesta-Munoz A, Raoul M et al. (1999) Mutants of glucokinase cause hypoglycaemia- and hyperglycaemia syndromes and their analysis illuminates fundamental quantitative concepts of glucose homeostasis. Diabetologia 42: 1175-1186

33. Ellard S, Beards F, Allmen LIS et al. (2000) A high prevalence of glucokinase mutations in gestational diabetic subjects selected by clinical criteria. Diabetologia 43: 250-253

34. Bartolotta E, Guazzarotti L, Blanché H, Clauin S, Morel V, Bellané-Chantelot C (1999) Prevalence of the maturity onset diabetes of the young (MODY) in the pediatric population of the Italy's Marche region. Diabetologia 42 [Suppl 1] A114 (Abstract)

35. Bertini C, Maioli M, Fresu P, Tonolo G, Pirastu M, Maioli $M$ (1997) A new missense mutation in the glucokinase 
gene in an Italian MODY family. Diabetologia 40: 1413-1414

36. Guazzini B, Gaffi D, Mainieri D et al. (1998) Three novel missense mutations in the glucokinase gene (G80S; E221 $\mathrm{K}$; G227C) in Italian subjects with maturity-onset diabetes of the young (MODY). Hum Mutat 12: 136

37. Prisco F, Iafusco D, Franzese A, Sulli N, Barbetti F (2000) MODY 2 presenting as neonatal hyperglycaemia: a need to reshape the definition of "neonatal diabetes" ? Diabetologia 43: 1331-1332

38. Rolland-Cachera MF (1993) Body composition during adolescence: methods, limitations and determinants. Horm Res 39: 25-40

39. Poskitt EME (1995) Defining childhood obesity: the relative body mass index (BMI). Acta Paediatr 84: 961-963

40. Schuster DP, Kien CL, Osei K (1998) Differential impact of obesity on glucose metabolism in black and white American adolescents. Am J Med Sci 316: 361-367

41. Glucksmann MA, Lehto M, Tayber O et al. (1997) Novel mutations and a mutational hotspot in the MODY3 gene. Diabetes: 1081-1086

42. Bell GI, Cuesta-Munoz A, Matschinsky FM (2000) Glucokinase. In: Creigton TE (ed) Encyclopedia of Molecular Medicine. John Wiley \& Sons, Inc. New York, (in press).
43. Burke CV, Buettger CW, Davis EA, McClane SJ, Matschinsky FM, Raper SE (1999) Cell-biological assessment of human glucokinase mutants causing maturity-onset diabetes of the young type 2 (MODY-2) or glucokinase-linked hyperinsulinaemia (GK-HI). Biochem J 342: 345-352

44. Luzi L, DeFronzo R (1989) Effect of loss of first-phase insulin secretion on hepatic glucose production and tissue glucose disposal in humans. Am J Physiol 257: E241-E246

45. Bruce DG, Chisholm DJ, Storlien LH, Kraegen EW (1988) Physiological importance of deficiency in early prandial insulin secretion in non-insulin-dependent diabetes. Diabetes 37: 736-744

46. Mitrakou A, Kelley D, Mokan M, Veneman T, Pangburn T, Reilly J, Gerich J (1992) Role of reduced suppression of glucose production and diminished early insulin release in impaired glucose tolerance. N Engl J Med 326: 22-29

47. Bruttomesso D, Pianta A, Mari A et al. (1999) Restoration of early rise in plasma insulin levels improves the glucose tolerance of type 2 diabetic patients. Diabetes 48: 99-105

48. Glaser B, Prebakaran K, Heyman M et al. (1998) Familial hyperinsulinism caused by an activating glucokinase mutation. N Engl J Med 338: 226-230 